\title{
ESTUDIO-TALLER BERROCAL: EXPERIMENTAR UN MUSEO DE OTRO MODO
}

\author{
BERROCAL STUDIO-WORKSHOP: \\ EXPERIENCING A MUSEUM IN ANOTHER WAY
}

Resumen

Palabras clave

Abstract

Keywords
Este artículo se compone de dos partes. En la primera, voy a ofrecer cinco razones de por qué este Estudio-taller permite experimentar de otro modo eso que llamamos «museo»: 1) Espacio de creación y creación de espacios; 2) Espacio de experimentación, no para ver de modo pasivo; 3 ) Experiencia personal, no masificada; 4) Volver: un criterio de distinción de una experiencia edificante; 5) Tiendas y fetichismo vs. Mundo de la obra. En cambio, en la segunda parte ofreceré una visión panorámica de lo que puede ser una visita al Estudio-Taller Berrocal, combinando información biográfica con su trayectoria artística y, sobre todo, con interpretaciones estéticas: 1) la Vanguardia de la Tradición; 2) el arte en la época de la reproductibilidad técnica; 3) Posmodernidad y diálogos intra-artísticos; 4) Arte, ciencia, tecnología.

Tradición-vanguardia, arte, experimentar, jugar, conocer, conversación pública, habitar.

This paper consists of two parts. In the first part, I will offer five reasons why this Studioworkshop allows us to experience what we call "museum" in another way: 1) Space of creation and creation of spaces; 2) Space of experimentation, not to see in a passive way; 3) Personal experience, not massified; 4) Return: a criterion of distinction of an edifying experience; 5) Tents and fetishism vs World of work. On the other hand, in the second part I will offer a panoramic vision of what a visit to the Berrocal StudioWorkshop could be, combining biographical information with its artistic trajectory and, above all, with aesthetic interpretations: 1) the avant-garde of Tradition; 2) art in the epoch of technical reproducibility; 3) Postmodernity and intra-artistic dialogues; 4) Art, science, technology.

Tradition, Avant-Garde, Art, Experimenting, Playing, Knowing, Public Conversation, Live. 


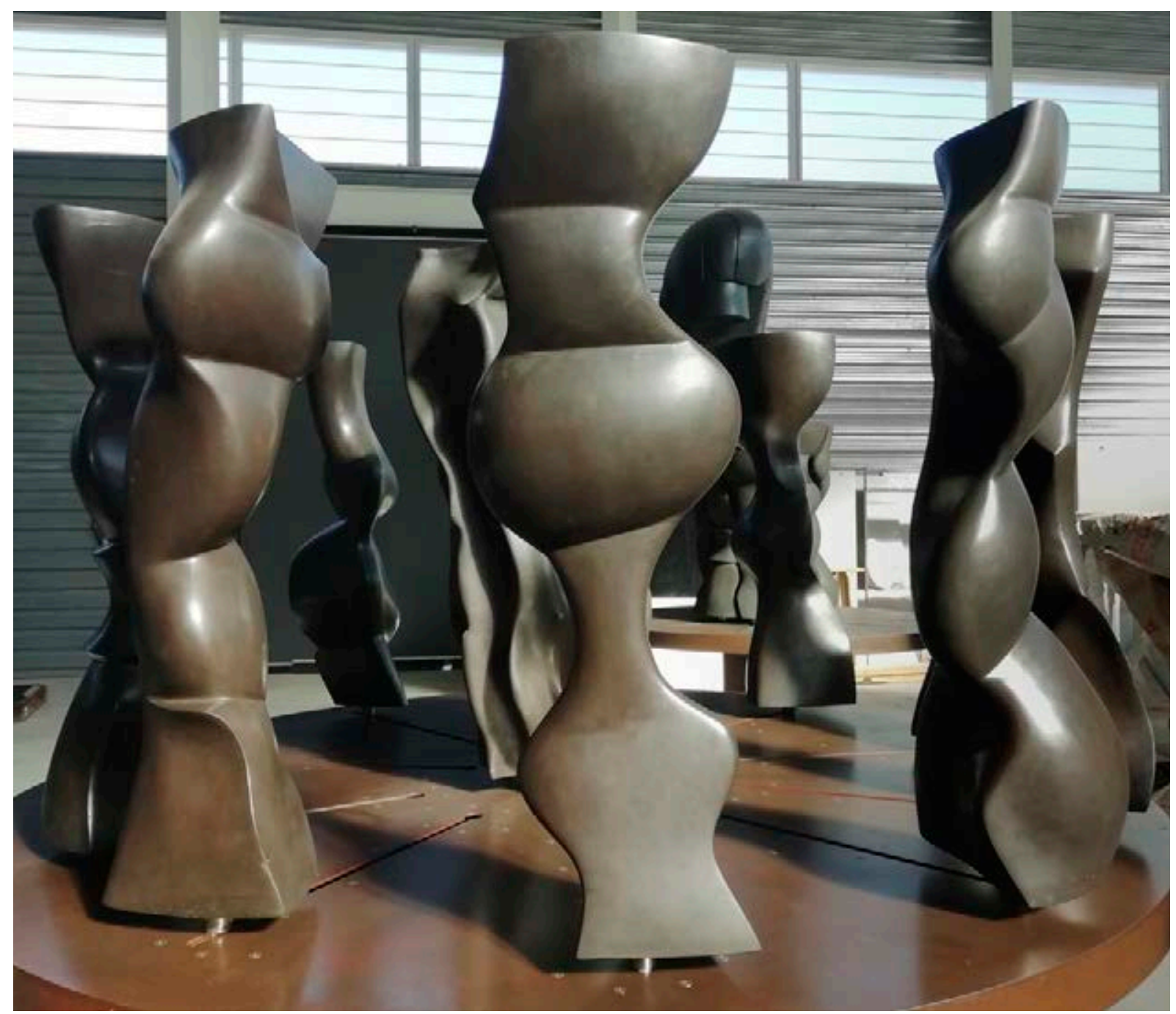

Opus 172 - Torso Cerruti, Miguel Berrocal, 1979

\section{Razones de ser diferente}

Vaya por delante que «lo diferente» no es un valor en sí, pues todo es en mayor o menor medida diferente con respecto a otros fenómenos de la realidad. En sentido riguroso, no existe nada igual. Es el lenguaje, sobre el cual articulamos el pensamiento complejo, lo que iguala las diferencias que produce la naturaleza y la cultura. Ahora bien, cuando hablamos de «museos diferentes» entendemos aquellos que por una serie de características y prácticas se distancian de lo que más o menos podemos considerar conven- cional. Dicho sea de paso: lo convencional no es incompatible con la excelencia. Pienso en el Metropolitan de New York o, sin ir más lejos, en el Museo del Prado de Madrid.

Aclarado esto, debo añadir que a mi juicio lo más determinante para producir una experiencia enriquecedora no es el museo en tanto que objeto de conocimiento, sino antes bien el sujeto, pues, como indicara Berkeley, «el sabor de la manzana no reside en esta, sino en el paladar de la misma». Se trata, pues, de una interacción. Por tanto, además de que el museo pueda contribuir a favorecer ese tipo de experiencias, lo idóneo es que los espectadores 
estén lo suficientemente cultivados, colaboren de manera cómplice y permanezcan abiertos a un buen encuentro. De acuerdo con el título elegido, a continuación voy a describir cinco razones de por qué el Estudio-Taller Berrocal ofrece experimentar el museo de otro modo.

1) Estudio-Taller: espacio de creación y creación de espacios. En primer lugar, no es un museo convencional, más exactamente es un estudio-taller. Eso sí, es un museo en tanto que conserva obras del escultor Miguel Berrocal (1933-2006). También repara y continúa proyectos inacabados. Pero, además, es un estudio-taller, es decir, el espacio donde en sus últimos años estudiaba, concebía y ejecutaba los distintos encargos que recibía.

Como estudio-taller, es un lugar privilegiado para conocer la obra de un artista, pues en cierto modo estos espacios son prolongaciones de la personalidad del creador: se puede apreciar el desordenado orden en el que trabajaba; la biblioteca en la que se documentaba y nutría; costumbres, rituales, manías, formas de proceder, en definitiva, información acerca de los procesos de creación. En un juego de palabras que nos permite retener la idea, lo he denominado «espacio de creación y creación de espacios», puesto que la escultura, al igual que la arquitectura, consiste fundamentalmente en crear espacios habitables, siquiera por la imaginación.

2) Espacio de experimentación, no para ver de modo pasivo. De acuerdo con una idea de uno de los más penetrantes pensadores de las artes, Paul Valéry, construyendo es como llegamos a conocer/nos (Valéry, 2004: 28). Junto con la concepción platónica de que creamos siguiendo unas ideas, he desarrollado este pensamiento de Valéry para comprender el proceso de creación bajo una dialéctica complementaria, reivindicando el arte como forma de conocimiento simbólico de la condición humana (Gámez Millán, 2018: 154-190).

Pues bien, en este estudio-taller, en contra de una práctica tradicional que impide tocar las piezas, más bien hay que indicar lo contrario: "prohibido no tocar» (Wagensberg, 2002: 108) -al menos ante determinadas obras-. Es más, las esculturas múltiples de Miguel Berrocal poseen una notable dimensión lúdica que invita a jugar, a construir y de-construir. De esta manera, mientras jugamos, podemos aprender a tomar conciencia de los volúmenes y de los espacios, y cómo se interrelacionan para crear vacíos, límites y formas inesperadas. El juego mantiene la motivación de aprender, por eso hay pocas experiencias comparables a aprender jugando o deleitándose (Schiller, 1981) (Huizinga, 1998).

3) Experiencia personal, no masificada. Hace unas tres décadas uno podía recorrer pasillos de museos como el Louvre sin cruzarse apenas con casi nadie. Actualmente esto es inimaginable. Cada vez más, los grandes museos -y no solo estos- se encuentran más masificados. ¿Cómo se puede tener una experiencia enriquecedora de esta forma? De este modo pueden conseguir el efecto contrario: producir rechazo, desaprobación o aburrimiento. La democratización de la cultura, sin la debida organización, sin una educación responsable, suele degenerar en banalización. A diferencia de otros museos, el Estudio-Taller Berrocal ofrece visitas guiadas de modo personal y de la mano de personas íntimamente vinculadas al artista, como sus hijos y/o su mujer, lo que incrementa el conocimiento de la vida y de la obra de este escultor.

4) Volver: un criterio de distinción de una experiencia edificante. El profesor y divulgador científico Jorge Wagensberg, que fue también el creador y el director del Museo de la Ciencia de Barcelona (CosmoCaixa) desde 1991 a 2005, sostenía que «lo importante de un museo no es que la gente vaya sino que la gente vuelva» (Wagensberg, 2006: 145). En la actualidad la mayoría de los museos persiguen alcanzar grandes cifras de asistencia de público, sin tener apenas 

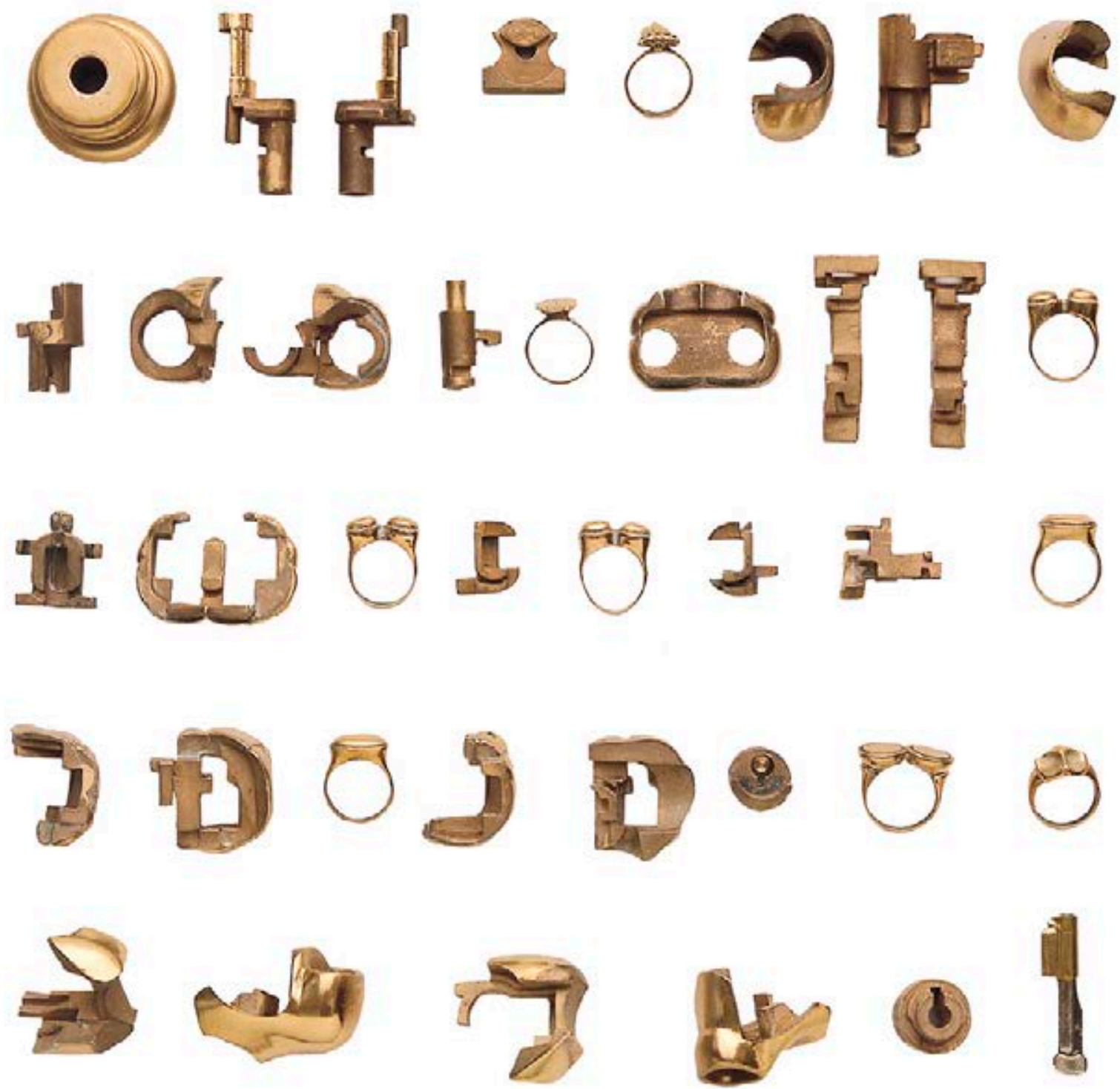

Opus 113 - Alexandre, Miguel Berrocal, 1969-1976

Imagen de la obra desmontada. Los 40 elementos que la componen

en cuenta qué experimentan durante la visita, cómo les afecta y altera, qué aprenden, qué se llevan. Sin embargo, del mismo modo que los libros que nos dejan huella no son tanto los que leemos como los que releemos (salvo que para releer es requisito indispensable haberlo leído, probado), las obras y museos que nos dejan huella son aquellos a los que volvemos.

Evidentemente, las cifras pueden medirse, y con ellas se justifican con frecuencia las políticas museísticas, incluso en términos de «me- jores» o «peores» museos según la cantidad de público. ¿Acaso no es una especie de dictadura de la cantidad? Equivalente, por cierto, a la tiranía de la mayoría en política. Quizá la experiencia y el aprendizaje no se pueden cuantificar o, por lo menos, resulta bastante más complicado. No obstante, sería interesante incorporar a los museos espacios donde se pueda recoger de algún modo estas experiencias y aprendizajes.

La historia del arte es inconcebible sin el diálogo entre artistas (Francisco Calvo Serra- 


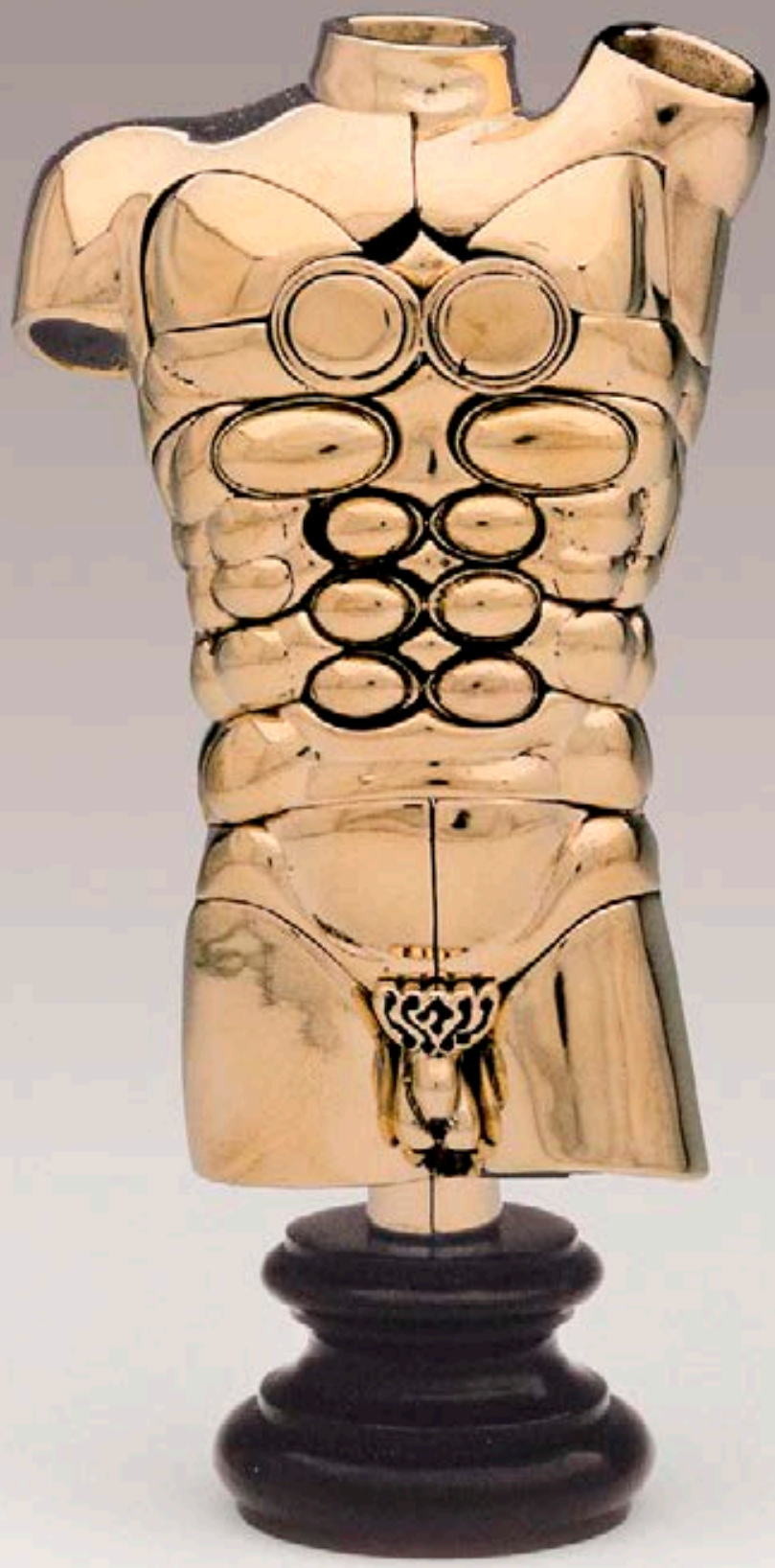

Opus 113 - Alexandre, Miguel Berrocal, 1969-1976. Imagen de la obra montada. La escultura se desmonta en 40 elementos

ller lo denominaba «diálogos intra-artísticos»): pienso en cómo Giorgione le responde a Tiziano con sus Venus, y a este último Velázquez; cómo Goya hace lo propio con Velázquez, y Manet, Ingres, Picasso, Matisse... No se trata de que todas las personas tengan que ser artistas, pero sí potenciar su capacidad creativa, sus habilidades, su capacidad de expresar, sentir, interactuar. Desde luego, es más enriquecedor que las personas que visiten un museo respondan con acciones y conversaciones... que con indiferencia, ya que esto es como si no hubiera pasado por el museo.

Como otros museos, este Estudio-Taller 


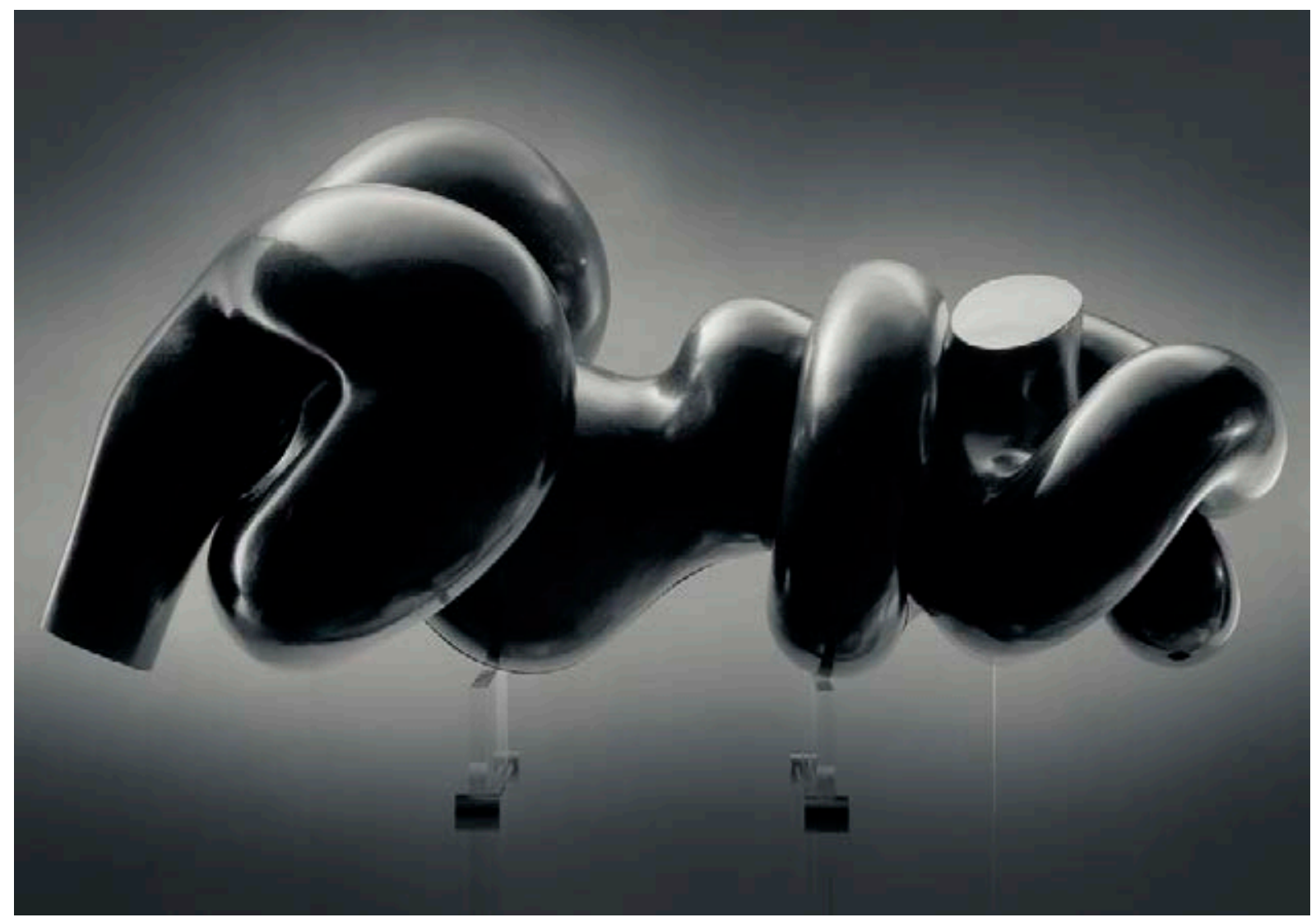

Opus 467 - Pepa, Miguel Berrocal, 1996-99

posee al final de la visita un libro de firmas para dejar constancia de la misma, de algunas impresiones o, con suerte, de parte de la experiencia adquirida, si uno acierta a formularla. Wagensberg apuntaba también que un buen museo es el que produce buena conversación. Conviene no perder de vista que existe una correlación entre la calidad de la conversación pública sobre determinados temas -pongamos arte, ciencia, educación, política...- y la calidad de una democracia, que depende del juicio y la libertad-responsabilidad de sus ciudadanos e instituciones.

5) Tiendas y fetichismo vs. mundo de la obra. Otro aspecto que distingue al Estudio-Taller Berrocal de otros museos es que carece de tienda al final de la visita. Puestos a vender productos con el fin de mantener el legado, encuentro interesante la propuesta que proponía Alain de Botton en un libro con multitud de ideas para renovar y reformar nuestra experiencia con el arte y los museos: «lo primordial no debería ser rodearnos de objetos con el nombre del artista y su obra, sino adquirir objetos que le hubieran gustado y estuvieran en consonancia con el espíritu de sus obras» (Botton, 2018: 77).

Ciertamente, antes que vender objetos de consumo que fomentan un fetichismo carente de sentido, pues a menudo estos objetos no guardan relación con la obra salvo por el nombre y acaso la reproducción a escala, entiendo que sería más edificante vender o permitir construir obras que prolonguen o amplíen los valores estéticos y ético-políticos de los artistas representados en el museo (simetría-igual- 


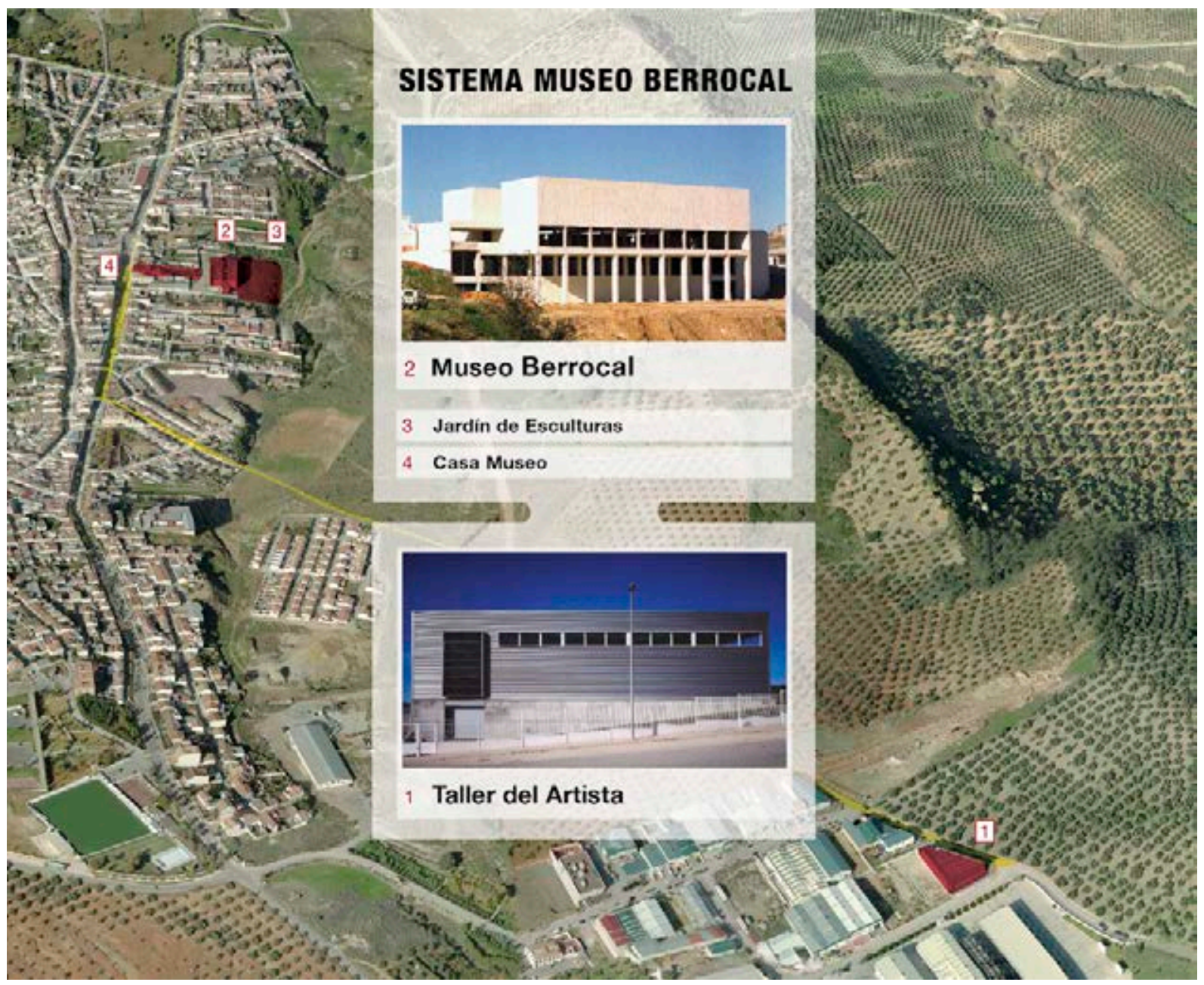

Sistema Museo Berrocal, conjunto museológico en torno a la obra del escultor Miguel Berrocal, situado en Villanueva de Algaidas (Málaga)

dad-justicia, proporción-mesura o moderación, innovación formal-libertad-responsabilidad, expresión-solidaridad-universalidad...).

\section{Recorrer el Estudio-Taller Berrocal}

Cerca de Antequera, una de las ciudades más bellas de Málaga, con el impresionante paisaje kárstico del Torcal, cuyas rocas sobre rocas guardan un aire de familia con las esculturas de Berrocal, y los dólmenes, declarados Patrimonio Mundial, concretamente en Villanueva de Algaidas, se encuentra el Estudio-Taller Berrocal, actual sede de la Fundación de este artista, que alberga su último taller de trabajo, su estudio, su biblioteca, con miles de volúmenes, una selección de obras concluidas y otras por concluir, en definitiva, una parte fundamental de su legado artístico, custodiado por Cristina de Braganza, su mujer, y sus dos hijos, que lo mantienen y lo difunden. De la mano de uno de ellos, Carlos, nos adentramos en el fascinante mundo de Berrocal.

Después de algunas décadas viviendo y trabajando en Verona, donde se había instalado tras pasar por Madrid, París y Roma porque disponía de mejores medios técnicos, industriales y económicos para desplegar su obra, y donde obtuvo la cima de su reconocimiento artístico, nombrado por el Ministro de Cultu- 
ra francés André Malraux «Chevalier de 1'Ordre des Arts et des Lettres» (1968), en contacto con la vanguardia internacional y exponiendo en museos y galerías del mundo, Miguel Berrocal (1933-2006) retornó junto con su familia los últimos años de su vida a su tierra nativa.

(Vanguardia de la tradición). Paralelamente a su licenciatura en Ciencias Exactas, Miguel Berrocal se forma en Madrid en la Escuela de Artes y Oficios bajo la dirección del maestro Ángel Ferrant, fecundo semillero de artistas. Comenzó estudiando arquitectura, y se inició en la pintura, pero a partir de 1955, en París, se inclinará por la escultura, a caballo entre la abstracción, dominante en su primera etapa, y una singular figuración (torsos sin cabeza y sin brazos, como si lo hubieran perdido en la erosión del decurso de los siglos, desnudos que se confunden con paisajes -anamorfosis-), constante ya hasta el final.

A pesar de que su obra está impregnada de influencias clásicas greco-latinas, es un profundo innovador dentro de la tradición. Si tuviera que sintetizar sus tres principales aportaciones a la escultura diría: en primer lugar, "análisis introspectivo de las formas», en términos de Pedro Feduchi, lo que le permite indagar y explorar lo que se ha denominado la cuarta dimensión del espacio. Recuérdese que Miguel Ángel había sostenido que la escultura está en el bloque, solo es necesario que las manos posean la suficiente habilidad para descubrir en él la idea que aparece en nuestra mente. Pues bien, en cierta manera esto es lo que consigue Berrocal descomponiendo cada obra en numerosos elementos.

En segundo lugar, vinculada con la anterior, la desmontabilidad de la escultura, es decir, no pocas de sus obras se componen y descomponen como puzles tridimensionales, lo que además de conferirle una perspectiva lúdica, ofrece en cierto modo la posibilidad de reproducir el proceso de (des)composición que ha llevado a cabo el artista durante la aventura creadora. (Me pregunto por qué no se ha establecido un paralelismo entre este método de Berrocal y la deconstrucción del filósofo Jacques Derrida, que encontró eco sobre todo en la arquitectura).

$\mathrm{Y}$, en tercer lugar, esta desmontabilidad logra que sus esculturas se compongan de «múltiples» elementos (en algunos casos de hasta 79) que tienen autonomía estética por sí mismos como si fueran piezas abstractas, pero que al montarse junto con las otras componen la figura escultórica. No obstante, como veremos a continuación, «múltiple» tiene en Berrocal otro sentido: reproducción de obras en serie.

(El arte en la época de la reproductibilidad técnica). Curiosamente el ensayo de Walter Benjamin en edición italiana se encuentra encima de su extensa mesa de trabajo, en la que podía estar trabajando alternativamente en cinco o seis proyectos. ¿Casualidad o causalidad? Benjamin argumentaba que en la época de la reproducción técnica se acabaría con «el aura» de las obras de arte, entendiendo por ello lo único e irrepetible de cada una. Quizá bajo esta luz algunos han criticado los «múltiples» de Berrocal, como si cediera ante los cantos de sirena del mercado.

Más bien lo concibo como una visionaria forma de adaptarse a sus circunstancias biográficas e históricas. Téngase en cuenta que por la precisión científica y la ejecución tan acabada de sus obras se necesitaba mucho tiempo para crear, y costes económicos y técnicos que de otro modo no hubiera podido sufragar. Sin embargo, bajo la idea de lo múltiple logra que los costes sean viables e incluso rentables, lo que le permitirá seguir investigando y creando. De camino consigue con un trabajo cooperativo y dirigido por él que el arte y, en particular la escultura, llegue a un público más amplio.

Es la época del pop art, cuya figura más reconocida acaso sea la de su amigo Andy Warhol, con un arte mecánico, replicable 


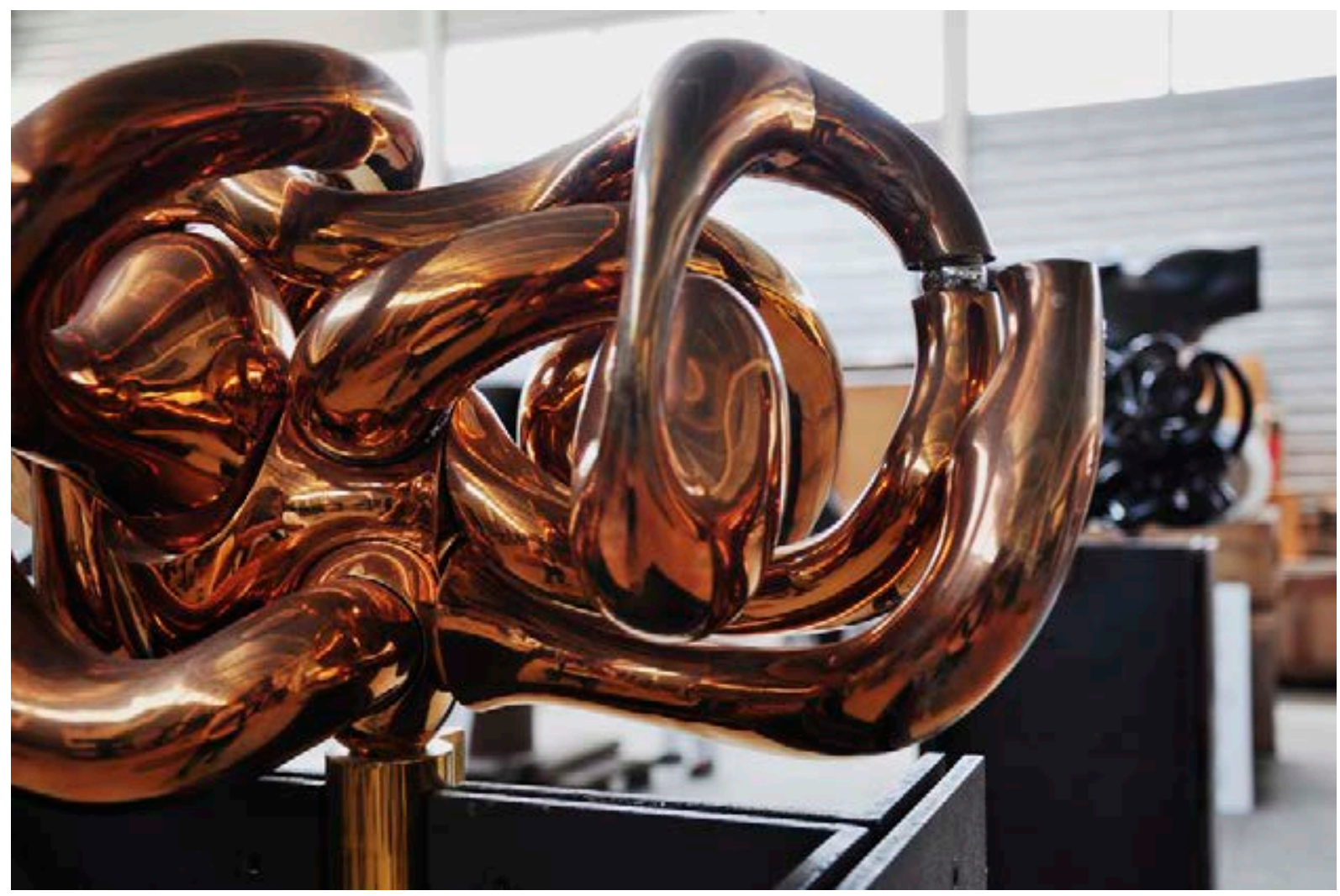

Opus 131 - Alhucema, Miguel Berrocal, 1974. Boceto para la escultura monumental Almudena, Fundación March, Madrid

y atractivo. La primera edición múltiple de Berrocal tiene lugar con María de la $O$ : 200 ejemplares. Es una obra que recibe el premio de Escultura en la Bienal de París (1966) y entra luego en la colección del Museum of Modern Art (MoMA) de New York. Posteriormente realizará ediciones de miles de ejemplares. Esta es la razón por la que hay en torno a 70.000 obras de Berrocal por el mundo. Algunas de ellas, deterioradas por algún accidente, retornan al taller. Otras de proyectos inacabados todavía aguardan por ver la luz. En contra de la célebre tesis de Benjamin, me pregunto si la multiplicidad de piezas, en vez de destruir el aura, no lo propagará.

(Posmodernidad y diálogos intra-artísticos). En las vitrinas con espejos de Berrocal observamos una serie de obras entre las que me llaman especialmente la atención aquellas en las que tiene lugar un diálogo intra-artístico. Por ejemplo, la Menina de la famosa pintura de Velázquez ha cobrado forma escultórica a la manera y gracia de Berrocal que, no contento con haberla trasladado a las tres dimensiones, provoca otros diálogos artísticos. Pues en el libro que acompaña a la escultura y en el que se describe con palabras en diferentes idiomas, dibujos, axonometrías y fotografías el proceso de creación, aparecen reveladores versos de Rafael Alberti: «Mi ansia es vivir en la espera / de que me miren por dentro / después de verme por fuera».

Pero el diálogo no termina ahí, y Enrique Morente le pone voz y música a los versos de Alberti, inspirados en la escultura de Berrocal, que a su vez se había desprendido de la pintura de Velázquez. Contamos, pues, con música, poesía, escultura, pintura... Algo similar sucede con un homenaje a Arcimboldo, precursor 
del surrealismo, que componía retratos de personas con frutas, flores, animales...También hay parodia en el Mini-David. Como escribiera Umberto Eco, «la respuesta posmoderna a lo moderno consiste en reconocer que, puesto que el pasado no puede destruirse -su destrucción conduce al silencio-, lo que hay que hacer es volver a visitarlo con ironía». Ironía y humor vibra en el homenaje a Dalí, titulado con un significativo juego de palabras: Dalirium.

(Arte, ciencia, tecnología). A lo largo del siglo xx tuvo lugar lo que el físico y novelista inglés C. P. Snow denominó en 1959 «las dos culturas», es decir, el «abismo de mutua incomprensión» entre los científicos y los intelectuales (Snow, 1977). Tengo para mí que ese distanciamiento entre las ciencias y las humanidades, incurriendo en los que Ortega y Gasset llamara «la barbarie del especialismo», es perjudicial para el desarrollo social de las culturas y la civilización. Como señalara uno de esos científicos y divulgadores que sabía conjugar maravillosamente lo más excelente de las ciencias naturales y humanas, Stephen Jay Gould, "no hay ciencia sin imaginación», del mismo modo que «no hay arte sin hechos» (Jay Gould, 2007: 45).

Si bien para algunos los «hechos» son exclusivos de las ciencias y la «imaginación» de las artes, en realidad ambas disciplinas requieren hechos, imaginación, hipótesis, ensayos, errores, experimentación, creatividad... Y otros aspectos que comparten en común. Y, en cualquier caso, como declaró Jay Gould, «para las maravillosas e iluminadoras diferencias entre las ciencias y las humanidades, todo al servicio potencial del único gran objetivo de la sabiduría, será mejor que estemos unidos, o con toda seguridad acabaremos colgados» (Jay Gould, 2010: 320).

Otro de los interesantes aspectos de la obra de Miguel Berrocal: la simbiosis entre arte, ciencia y tecnología. Su arte es inconcebible sin la ciencia y la tecnología de su época. Es una de las razones por las que se instaló en Verona. Se diría que en su proceso de creación se sirve del dibujo, que puede considerarse seminal en el despliegue de las artes, pero en su ejecución observamos cómo se alían valores técnicos, tecnológicos y artísticos, tales como el orden, el mecanicismo, la proporción, la simetría o la belleza.

En el Estudio-Taller Berrocal, actual sede de la Fundación Berrocal (www.berrocal.net), que abre las puertas al público previa reserva, tendrán el placer de conocer detalladamente la trayectoria y los procesos de creación de uno de los más brillantes escultores de las últimas décadas. Pero aún queda mucho por estudiar y difundir: por ejemplo, los sorprendentes vasos comunicantes entre artes y ciencias que se aprecia en la obra de este creador, sus métodos de investigación y experimentación, el valor proyectivo del dibujo, su interdisciplinariedad... Y que el polen seminal de su obra se extienda entre artistas.

\section{BibliografíA}

AzúA, Félix (2017) Diccionario de las Artes, Barcelona: Debate.

Botton, Alain de y Armstrong, John (2018) El arte como terapia, trad. Ricardo García y Elena Aranaz, Hong Kong: Phaidon.

Dewey, John (2008) El arte como experiencia, trad. Jordi Claramonte, Barcelona: Paidós.

Gámez Millán, Sebastián (2018) Conocerte a través del arte, Madrid: Ilusbooks.

HuizingA, Johan (1998) Homo ludens, trad. Eugenio Imaz, Madrid: Alianza.

JAy Gould, Stephen (2007) Acabo de llegar. El final de un principio en historia natural, trad. Joandomènec Ros, Barcelona: Crítica.

- (2010) Érase una vez el zorro y el erizo. Las humanidades y las ciencias en el tercer milenio, trad. 


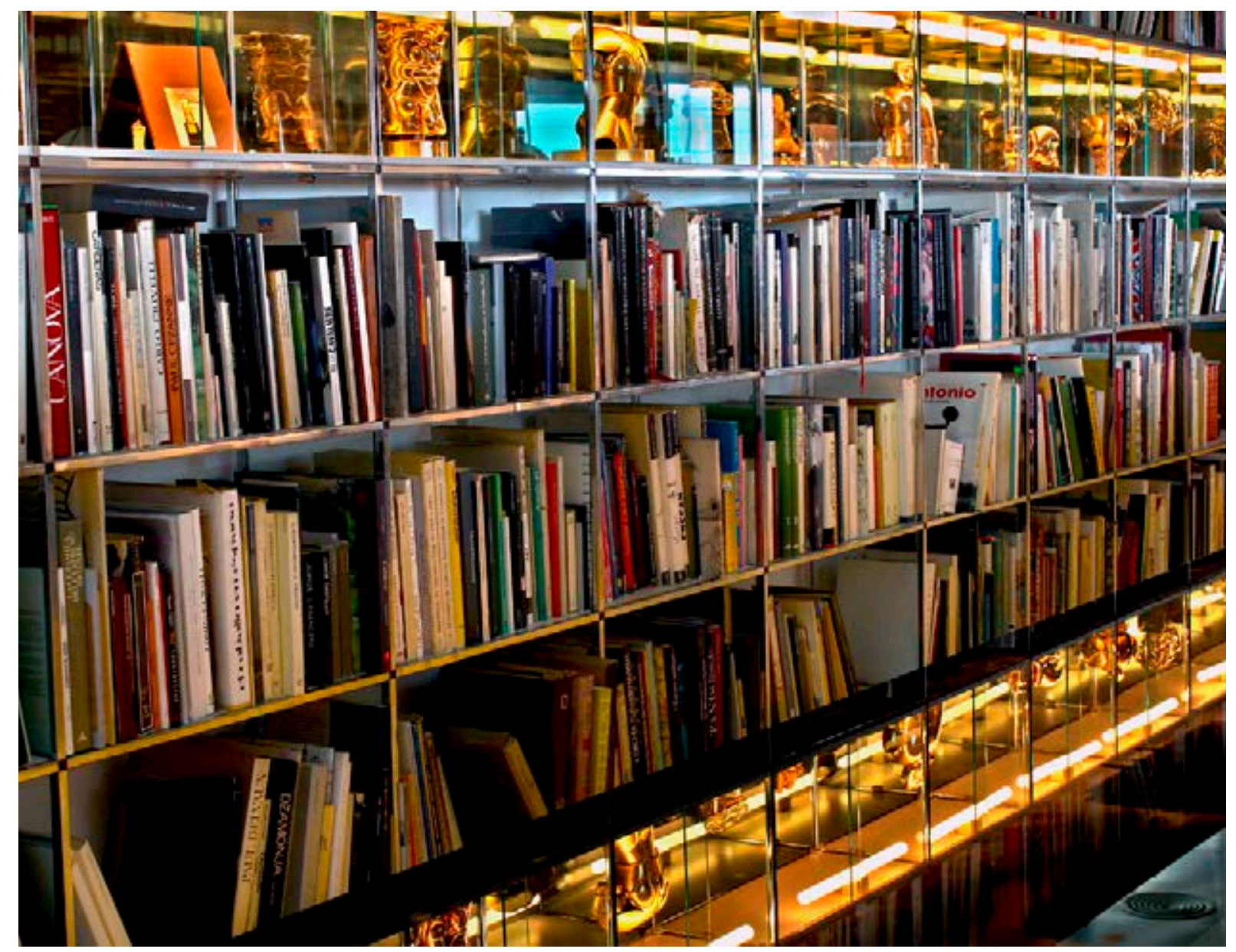

Estudio-taller Berrocal. Vista de la biblioteca de 5000 volúmenes y de parte de la colección de múltiples

Joandomènec Ros, Barcelona: Crítica.

Malraux, André (2017) El Museo Imaginario, trad. María Condor, Madrid: Cátedra.

SÁnchez Saiz, Eulogio y Martínez Silvente, María Jesús (2018) AtrapArte. Dudas y vivencias en el arte contemporáneo, Santander: El Desvelo.

Santayana, George (2002) El sentido de la belleza. Un esbozo de teoría estética, trad. Carmen García Trevijano, Madrid: Tecnos.

SCHILler, Friedrich (1981) Cartas sobre la educación estética del hombre, trad. Vicente Romano García, Madrid: Aguilar.

Shusterman, Richard (2002) Estética pragmatista. Viviendo la belleza, repensando el arte, trad. Fernando González del Campo Román, Barcelona: Idea Books.

SNow, C. P. (1977) Las dos culturas y un segundo enfoque, trad. Salustiano Masó, Madrid: Alianza.

VALÉRY, Paul (2004) Eupalinos o el arquitecto, trad. José
Luis Arantegui, Madrid: Antonio Machado.

VV.AA. (2000) Berrocal, Madrid: Unicaja.

WAgENSBERG, Jorge (2002) Si la Naturaleza es la respuesta, ¿cuál era la pregunta? Y otros quinientos pensamientos sobre la incertidumbre, Barcelona: Tusquets.

- (2006) A más cómo, menos por qué. 747 reflexiones con la intención de comprender lo fundamental, lo natural y lo cultural, Barcelona: Círculo de Lectores.

- (2014) Elpensadorintruso. El espíritu interdisciplinario en el mapa del conocimiento, Barcelona: Tusquets.

www.berrocal.net

Recibido el 26 del 8 de 2019

Aceptado el 4 del 11 de 2019 BIBLID [2530-1330 (2019): 62-73] 